\title{
Local B cells and $\lg E$ production in the oesophageal mucosa in eosinophilic oesophagitis
}

\author{
M Vicario, ${ }^{1,2} \mathrm{C}$ Blanchard, ${ }^{1} \mathrm{~K}$ F Stringer, ${ }^{3} \mathrm{M} \mathrm{H}$ Collins, ${ }^{3} \mathrm{M} \mathrm{K} \mathrm{Mingler,}{ }^{1}$ A Ahrens, ${ }^{1}$ \\ P E Putnam, ${ }^{4}$ J P Abonia, ${ }^{1} \mathrm{~J} \mathrm{Santos}^{2}{ }^{2} \mathrm{M}$ E Rothenberg ${ }^{1}$
}

\begin{abstract}
${ }^{1}$ Division of Allergy and Immunology, Department of Pediatrics, Cincinnati Children's Hospital Medical Center, University of Cincinnati College of Medicine, Cincinnati, Ohio, USA; ${ }^{2}$ Digestive Diseases Research Unit, Neuro-immunogastroenterology Lab,

Department of Gastroenterology, Institut de Recerca \& Hospital Universitari Vall d'Hebron, Universitat Autònoma de Barcelona, Barcelona, Spain;

${ }^{3}$ Division of Pathology and Laboratory Medicine,

Department of Pediatrics, Cincinnati Children's Hospital Medical Center, University of Cincinnati College of Medicine, Cincinnati, Ohio, USA; ${ }^{4}$ Division of Gastroenterology, Hepatology and Nutrition, Department of

Pediatrics, Cincinnati Children's Hospital Medical Center, University of Cincinnati College of Medicine, Cincinnati, Ohio, USA
\end{abstract}

Correspondence to: Professor M E Rothenberg, Division of Allergy and Immunology, Department of Pediatrics, Cincinnati Children's Hospital Medical Center

University of Cincinnati College of Medicine, 3333 Burnet Avenue, Cincinnati, $\mathrm{OH}$ 452293039, USA; rothenberg@ cchmc.org

Revised 27 May 2009 Accepted 29 May 2009 Published Online First

14 June 2009

\begin{abstract}
Background: Eosinophilic oesophagitis (EO) is an emerging yet increasingly prevalent disorder characterised by a dense and selective eosinophilic infiltration of the oesophageal wall. While EO is considered an atopic disease primarily triggered by food antigens, disparities between standard allergen testing and clinical responses to exclusion diets suggest the participation of distinct antigen-specific immunoglobulin $\mathrm{E}(\lg \mathrm{E})$ in the pathophysiology of EO.
\end{abstract}

Aim: To find evidence for a local lgE response.

Methods: Endoscopic biopsies of the distal oesophagus of atopic and non-atopic EO and control individuals (CTL) were processed for immunohistochemistry and immunofluorescence to assess the presence of B cells, mast cells, and IgE-bearing cells. Oesophageal RNA was analysed for the expression of genes involved in B cell activation, class switch recombination to $\lg E$ and $\lg E$ production, including germline transcripts (GLTs), activation-induced cytidine deaminase (AID), IgE heavy chain $(\mathrm{C} \varepsilon)$ and mature $\lg \mathrm{E}$ mRNA using polymerase chain reaction and microarray analysis.

Results: Regardless of atopy, EO showed increased density of B cells $(p<0.05)$ and of IgE-bounded mast cells compared to CTL. Both EO and CTL expressed $\mu \mathrm{GLT}$, $\varepsilon \mathrm{GLT}, \gamma 4 \mathrm{GLT}, \mathrm{AID}, \mathrm{C} \varepsilon$ and $\lg \mathrm{E}$ mRNA. However, the frequency of expression of total GLTs ( $p=0.002)$, $\varepsilon \mathrm{GLT}$ $(p=0.024)$, and $C \varepsilon(p=0.0003)$ was significantly higher in EO than in CTL, independent of the atopic status.

Conclusion: These results support the heretofore unproven occurrence of both local immunoglobulin class switching to $\lg E$ and $\lg E$ production in the oesophageal mucosa of EO patients. Sensitisation and activation of mast cells involving local lgE may therefore critically contribute to disease pathogenesis.

Eosinophilic oesophagitis (EO) is a chronic inflammatory disorder, restricted to the oesophagus, whose pathogenesis is poorly understood. Studies from North America, ${ }^{1}{ }^{2}$ Europe $^{3}$ and Australia ${ }^{4}$ have indicated that EO is a growing health problem worldwide with an annual incidence of $\geqslant 1$ in $10000 .^{5}$ Patients with primary EO often report symptoms (chest and abdominal pain, dysphagia, heartburn, vomiting, and food impaction) also observed in gastro-oesophageal reflux disease (GORD) or chronic oesophagitis. However, in contrast to GORD patients, $\mathrm{EO}$ patients are predominantly males, ${ }^{3}$ have a familial pattern of inheritance, ${ }^{6}$ do not respond to treatment with proton pump inhibitors (PPIs), have normal $\mathrm{pH}$ monitoring, ${ }^{78}$ show extensive epithelial hyperplasia and higher density of eosinophils ( $>15$ peak eosinophils/high-power field) in the oesophageal epithelium, and over-express a unique transcriptome including the eosinophil chemokine eotaxin3. ${ }^{9}{ }^{10}$

Several lines of evidence support the view that EO is an atopic disorder. ${ }^{11}{ }^{12}$ Most patients with EO ( $~ 75 \%$ of cases) show signs of atopy, defined by reactivity to allergens by skin-prick testing (SPT) or identification of specific $\operatorname{IgE}$ in serum. ${ }^{512}{ }^{13}$ Furthermore, EO appears to be primarily food antigen-driven since $>90 \%$ of patients achieve complete remission following an elemental dietbased nutrition. ${ }^{14}$ However, despite the high rate of sensitisation to specific food antigens, the benefit of removing SPT-based exclusion diets is commonly unsatisfactory. ${ }^{15} 16$ Perhaps the identification of antigen sensitisation via cutaneous testing is not reflective of the presumably IgE bound to mast cells (or basophils) in the oesophageal mucosa.

Mast cells are resident cells of the oesophagus, shown previously to be increased in number and to correlate with eosinophil counts and eotaxin-3 in the mucosa of EO patients. ${ }^{10}{ }^{17}$ In addition, the transcription of some mast cell-specific genes, such as carboxypeptidase A3, high-affinity IgE receptor (FceR1) and tryptase- $\alpha$ is higher in oesophageal biopsies from patients with EO compared with healthy controls. ${ }^{10}$ These findings, together with the presence of mast cells in the oesophagus of patients with EO, ${ }^{10}{ }^{17-19}$ suggest a putative role for mast cell-mediated hypersensitivity in the pathogenesis of $\mathrm{EO}$.

The oesophageal mucosa displays a strong immunological capacity conveyed via a diversity of resident immune cell types, ${ }^{18}{ }^{20}$ well represented by its known ability to recruit acute inflammatory cells and eosinophils. ${ }^{21}{ }^{22}$ In particular, the presence of interleukin 4 (IL4) and IL13, ${ }^{22}$ B cells ${ }^{18}$ and of cells that are potentially $\mathrm{CD}_{40 \mathrm{~L}^{+}}$(eg, T cells and mast cells) in the oesophagus supports its participation in allergen sensitisation and IgE production, highlighting a potential role for B lymphocytes and mast cells in this disease. Following antigen stimulation, mature B lymphocytes undergo class switch recombination (CSR) by changing the $\mathrm{C}$ region of the $\mathrm{Ig} \mathrm{H}$ chain $\left(\mathrm{C}_{\mathrm{H}}\right)$ with a downstream region on human chromosome $14,{ }^{23}$ therefore improving the antibody effector function and contributing to the maturation of the humoral response. $^{24}{ }^{25}$ Induction of CSR to $\operatorname{IgE}$ requires mature B cells, IL4 or IL13, cognate help by CD40$\mathrm{L}^{23} 24$ and upregulation of activation-induced cytidine deaminase (AID) ${ }^{26}{ }^{27}$ CSR involves the transcription of germ-line genes, DNA recombination within the heavy chain locus producing $\varepsilon$ circular
This paper is freely available online under the BMJ Journals unlocked scheme, see http:// gut.bmj.com/info/unlocked.dtl 
Table 1 Clinical characteristics of patients with eosinophilic oesophagitis and of control patients

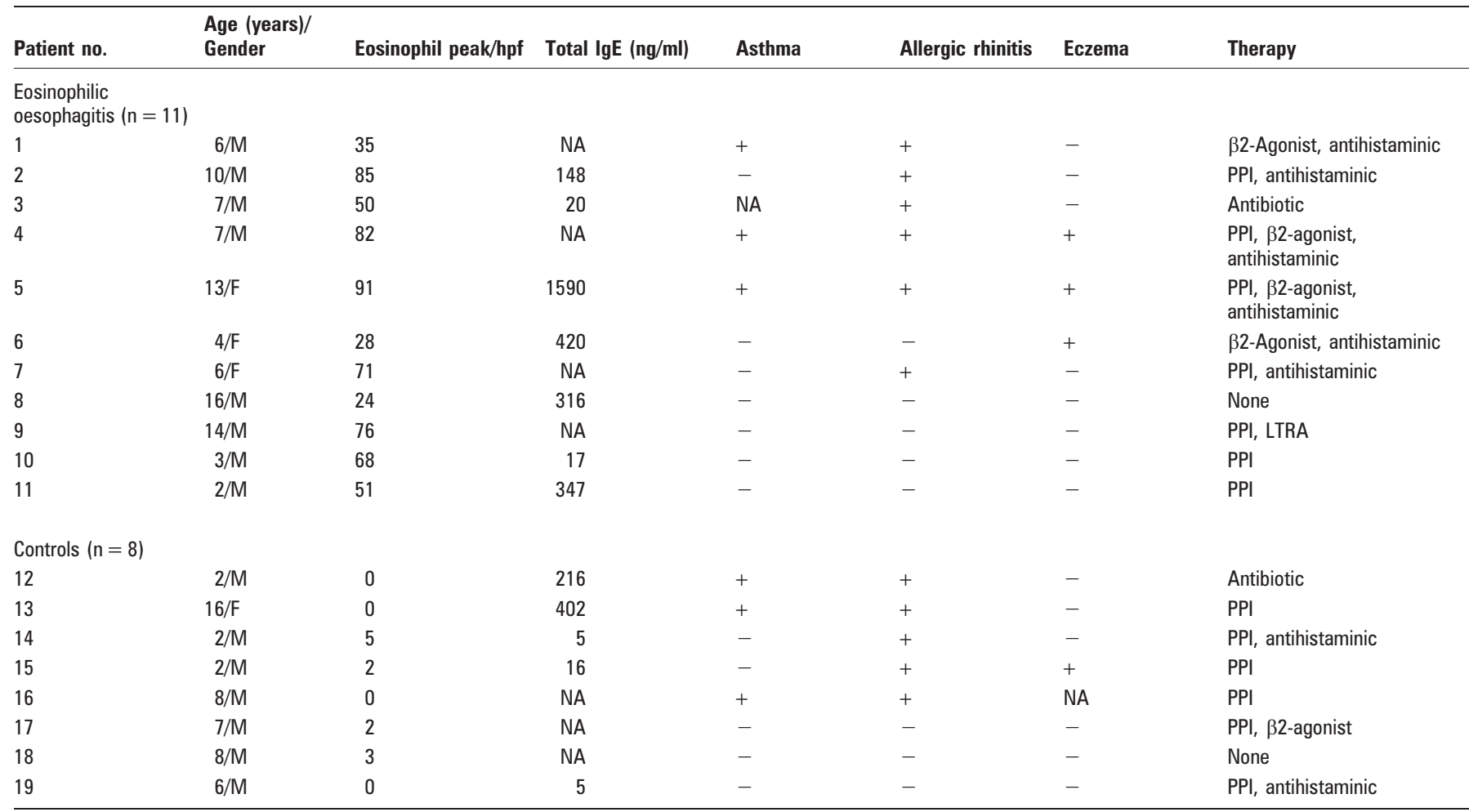

Serum IgE concentration in control individuals was $96 \mathrm{ng} / \mathrm{ml}^{34}$

F, female; hpf, high-power, field; IgE, immunoglobulin E; LTRA, leukotriene receptor antagonist; M, male; NA, not available; PPI, proton pump inhibitor.

transcripts, and the synthesis of immunoglobulin mature mRNA that is translated into protein. ${ }^{23}$ Although this phenomenon has been generally assumed to be restricted to lymphoid organs, ${ }^{28}{ }^{29}$ recent studies have demonstrated that other tissues under constant antigenic challenge such as the intestinal, ${ }^{30}{ }^{31}$ nasal $^{32}$ and bronchial ${ }^{33}$ mucosa support isotype switching and IgE production.

We hypothesised that the oesophageal mucosa acts as a site for IgE generation in EO. We examined a cohort of paediatric patients and studied B cell levels in the oesophageal mucosa, and the molecular steps involved in CSR to IgE. Our results identify the human oesophagus as an immunologically active tissue with regard to $\mathrm{B}$ cell antibody production, suggesting a role for $\mathrm{B}$ lymphocytes and local IgE synthesis in EO and implicating local IgE-mediated mast cell degranulation as an important contributor to $\mathrm{EO}$ pathogenesis.

\section{MATERIALS AND METHODS}

\section{Oesophageal biopsies and patient characteristics}

Patients were retrospectively selected without any regard to age, atopic status, or gender from our database at the Division of Pathology and Laboratory Medicine at Cincinnati Children's Hospital Medical Center. Biopsy specimens were collected from the distal oesophagus, fixed in formalin and processed for pathological analysis with haematoxylin \& eosin (H\&E) staining. Diagnosis of EO was established by a pathologist based on a maximum eosinophil count of $\geqslant 15$ eosinophils per high-power field (hpf, $\times 400$ ), the presence of inflammatory infiltrate, and the hyperplasia of the basal epithelial layer. The control group (CTL) included patients with symptoms typical of GORD and EO, most of them under PPI therapy, which showed normal endoscopic and histological evaluation and the presence of $\leqslant 5$ eosinophils/hpf. We first studied the cellular infiltrate and the expression of B cell-related genes in patients from our database regardless of therapy, and thereafter selected a cohort of patients without corticosteroids or diet therapy to assess molecular markers of CSR and IgE synthesis. The detailed clinical characteristics of the selection of EO and CTL patients including eosinophil counts in the oesophageal epithelium, atopic status and therapy are shown in table 1. Patients suffering from asthma, allergic rhinitis or eczema were defined as atopic. Due to the low amount of biological material derived from endoscopic oesophageal biopsies from paediatric patients, not all samples could be processed for all experimental procedures.

\section{Immunohistochemistry}

Formalin-fixed, paraffin-embedded biopsies were sectioned at $4 \mu \mathrm{m}$ and stained with antibodies following standard procedures. B lymphocytes were identified with mouse anti-human CD20 (Dako, XXXXX, California, USA), and mast cells with mouse anti-human tryptase (Cell Marque, Rocklin, California, USA). Staining was developed with the LSAB ${ }^{\circledR} 2$ System-HRP (Dako, Carpinteria, California, USA). Sections of human tonsils and nasal polyp were used as positive control for CD20 or tryptase staining, respectively. The primary antibody was omitted as a negative control. One biopsy section from each patient was subjected to CD20 or tryptase staining. Morphometric analysis was performed for quantification of $\mathrm{CD}^{2} 0^{+}$cells using the Metamorph Imaging system (Universal Imaging, West Chester, Pennsylvania, USA). Total stained cells and total surface area were quantified in the three compartments of the oesophageal mucosa: the epithelium, the vascular papillae (projections of the lamina propria towards the undersurface of the epithelium) ${ }^{35}$ and the lamina propria, and results are expressed as number of positive cells per $\mathrm{mm}^{2}$ of tissue. Tryptase $^{+}$cells were counted in at least 10 non-overlapping 
Figure 1 Detection of $B$ cells in the oesophageal mucosa. (A) Representative micrographs of the CD20 staining in the epithelium, the vascular papillae and the lamina propria of the oesophageal biopsies of EO and CTL subjects. (B) Density of $B$ cells in each compartment of the oesophageal biopsies of EO $(n=21)$ and CTL $(n=12)$ groups. Atopic (open symbols) and non-atopic patients (dark symbols) are indicated. The lines represent the median value in each group. Groups were compared using the nonparametric Mann-Whitney $U$ test and $p$ values are indicated. (C) Microarray analysis of the transcripts of upregulated $B$ cell-related genes in the oesophageal biopsies of EO $(n=13)$ and CTL $(n=13)$ patients. RNA from each patient was subjected to chip analysis using Affymetrix Human Genome U133 Plus 2.0 Gene Chips. Affymetrix accession number of genes and their fold change expression in EO with respect to CTL are indicated. Statistical analysis was performed using the Welch T test; $p$ values are indicated ( $n=13$ for EO and CTL groups). CTL, control; EO, eosinophilic oesophagitis.
A.

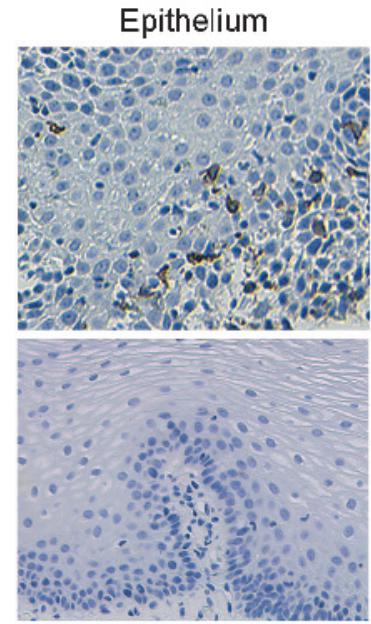

Vascular papillae

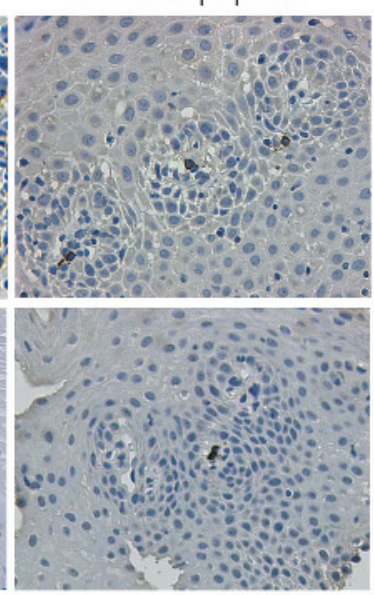

B.
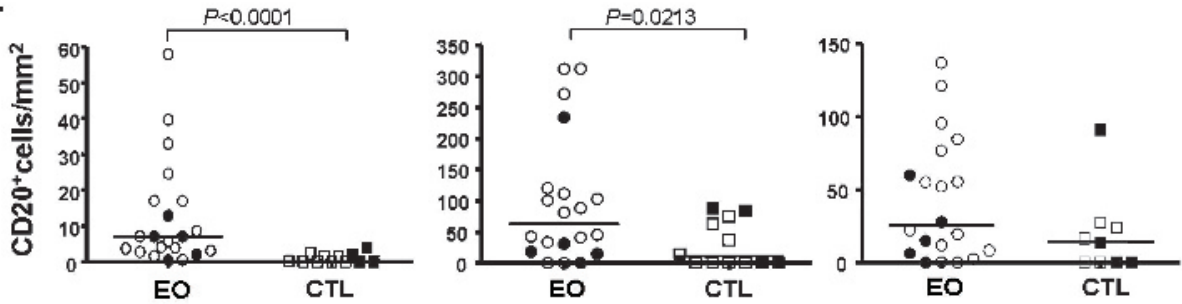

C

\begin{tabular}{|c|c|c|c|}
\hline Affy\# & Fold change & P value & Symbol \\
\hline 214677 x_at & 12.33 & 0.00002 & |GLC2 \\
\hline $\begin{array}{l}217022 \text {-5_at } \\
212592 \text { at }\end{array}$ & $\begin{array}{l}1211 \\
8.7608\end{array}$ & $\begin{array}{l}0.00005 \\
0.00042\end{array}$ & $\begin{array}{l}\text { IGHD } \\
\text { IGJ }\end{array}$ \\
\hline $\begin{array}{l}1553395 \text { _a_at } \\
207496 \text { at }\end{array}$ & $\begin{array}{l}5.587 \\
5.471\end{array}$ & $\begin{array}{l}000006 \\
0.00000\end{array}$ & $\begin{array}{l}\text { CD2OOR1 } \\
\text { MSAA2 }\end{array}$ \\
\hline $\begin{array}{l}206172 \text { _at } \\
216401 \text { _x_at }\end{array}$ & $\begin{array}{l}4.636 \\
2.383\end{array}$ & $\begin{array}{l}0.00008 \\
0.01630\end{array}$ & $\begin{array}{l}\text { IL13RA2 } \\
\text { IGKV }\end{array}$ \\
\hline 202491_s_at & 1.955 & 0.00005 & IKEKAPP \\
\hline $\begin{array}{l}\text { 203066_at } \\
\text { 223502_s_at } \\
\text { 206126_at }\end{array}$ & $\begin{array}{l}1.913 \\
1.528 \\
1.271\end{array}$ & $\begin{array}{l}0.00008 \\
0.04320 \\
0.03110\end{array}$ & $\begin{array}{l}\text { GALNAC4S-8ST } \\
\text { TNFSF13B } \\
\text { BLR1 }\end{array}$ \\
\hline 207433 at & 1.233 & 0.03760 & IL10 \\
\hline
\end{tabular}

Gene name

Imunoglobulin lambda jciring 3

Immunoglobulin heavy constan: delts
Irrirnunuglobulir J polypeptide, inker potein for

immunoglobulin alpha and mu polypeptides

CD200 receptor 1

Memorane-spanning 4-domains, subfarmily $A$, memser 2 ( $F e$ fragment of igE, high affinityl: receptor for; beta po ypeptide)

Interleukin 13 receptor, alpha 2
Homo sapiens partial IGKV gere for immunoglobulin kappo

polypeptide gene enhancer ir B-cells, Kina complex-associated protein

umor necrosis factor (ligand) superfamily member 13b Burkitt lymphoma receptor 1 , GTP binding protein chemokine ( $C-X-C$ motif) receptor 5 ) interleukin 10 fields and the results are expressed as the maximum number of positive cells per hpf.

\section{Immunofluorescence}

Double immunofluorescence staining was performed in sidemounted paraffin sections. Mast cells were identified with rabbit anti-human CD117 (Cell Marque) and IgE-bearing cells with chicken anti-human IgE (Genway Biotech, San Diego, California, USA) primary antibodies. Secondary antibodies were Alexa Fluor 488-labelled goat anti-rabbit (Invitrogen, Carlsbad, California, USA) and biotinylated donkey anti-chicken (Jackson Labs, West Grove, Pennsylvania, USA), following Alexa Fluor
Figure 2 Mast cell counts in the oesophageal epithelium of EO and CTL patients. (A) Atopic (open symbols) and non-atopic patients (dark symbols) are indicated. The lines represent the median value in each group. The maximum cell count per hpf in each group was compared using the Mann-Whitney $U$ test and the $p$ value is indicated (EO $\mathrm{n}=18 ;$ CTL $\mathrm{n}=8$ ). (B) Correlation between density of $B$ cells and mast cells counts in the oesophageal epithelium of EO and CTL patients was calculated with the Spearman rank correlation test $\left(p=0.0015 ; r^{2}=0.554\right)$. Different units in each axis derive from the different methodology to assess cell counts. CTL, control; EO, eosinophilic oesophagitis.
A.

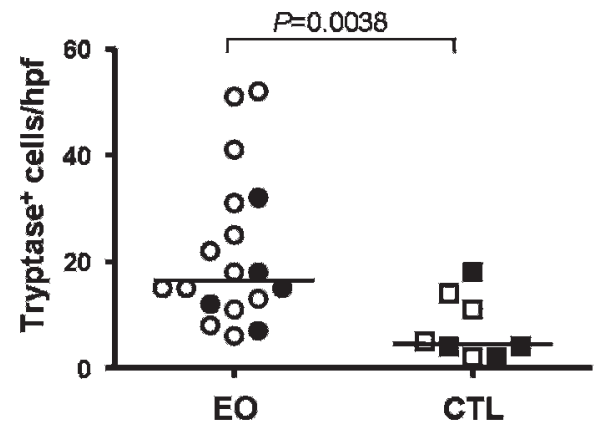

B.

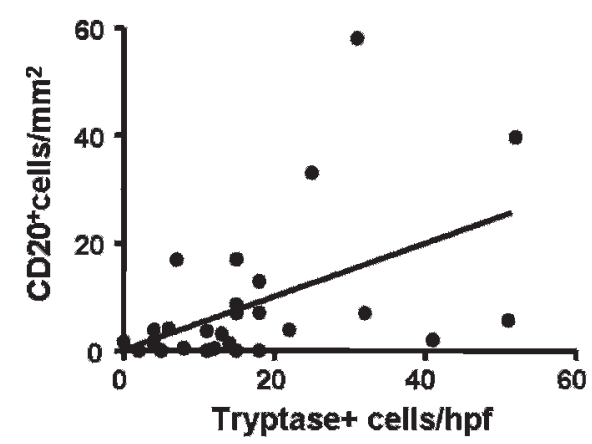


594 labelled streptavidin (Invitrogen). Slides were cover-slipped using antifade medium containing 4',6-diamidine-2'-phenylindole dihydrochloride (DAPI) (Prolong Gold; Invitrogen) and assessed and photographed using an RT Slider digital camera (Diagnostic Instruments, Sterling Heights, Michigan, USA) mounted on an E600 fluorescence microscope (Nikon Instruments, Melville, New York, USA). Nasal polyp biopsy sections from an allergic patient were used as positive control tissue. Isotype-matched control antibodies were used as negative control. Results are expressed as the maximum number of stained cells per reticle area using a Nikon CF1 $\times 10$ eyepiece.

\section{RNA isolation and DNA microarray analysis}

Each biopsy from the distal oesophagus was immediately immersed in RNAlater (Qiagen, Germantown, Maryland, USA) and stored at $4^{\circ} \mathrm{C}$. Total mRNA was isolated using the RNAeasy Mini Kit (Oiagen) and hybridisation to DNA microarray was performed by the Microarray Core. Microarray analysis and assessment of transcripts from B lymphocyte-related genes were performed as previously described. ${ }^{36}$

\section{Reverse transcription polymerase chain reaction and PCR analysis}

The RNA samples (500 ng) were subjected to reverse transcription analysis using Inscript reverse transcriptase (Bio-Rad Laboratories, Hercules, California, USA) following the manufacturer's instructions. Germ-line transcripts (GLTs) from $\varepsilon$ GLT, $\mu$ GLT, $\gamma 1$ GLT and $\gamma 4$ GLT, and AID mRNA were amplified with validated primer sets. ${ }^{32}$ Mature IgE mRNA was amplified with primers $\mathrm{JH}^{37}$ and $\mathrm{C} \varepsilon \mathrm{R}$ (5'-CAGGACGAC TGTAAGATCTTCACG). To assure the integrity and to control the load of cDNA, glyceraldehyde-3-phosphate dehydrogenase was amplified with primers GAPDH-F (5'-TGGAAATCCC ATCACCATCT) and GAPDH-R (5'-GTCTTCTGGGTGGCA GTGAT). PCR was run in a $23 \mu$ reaction in the ready-to-use Supermix PCR mixture (Invitrogen) containing $3 \mu$ of template and the corresponding primers at $0.22 \mu \mathrm{mol} / 1$. For AID amplification, the two rounds of PCR were: denaturation at $96^{\circ} \mathrm{C}$ for $10 \mathrm{~min}$, following 25 cycles of denaturation at $96^{\circ} \mathrm{C}$ for $1 \mathrm{~min}$, annealing at $60^{\circ} \mathrm{C}$ for $1 \mathrm{~min}$ and elongation at $72^{\circ} \mathrm{C}$ for $2 \mathrm{~min}$, and a final extension at $72^{\circ} \mathrm{C}$ for $5 \mathrm{~min}$. Similar conditions were used to amplify GLT and IgE mRNA, with 30 s time on each step of the 50 or 45 PCR cycles, respectively, and annealing temperature of $60^{\circ} \mathrm{C}$ for $\varepsilon \mathrm{GL}, 55^{\circ} \mathrm{C}$ for $\mu \mathrm{GLT}$, $\gamma 1 \mathrm{GLT}$ and $\gamma 4 \mathrm{GLT}$, and $57^{\circ} \mathrm{C}$ for IgE mRNA. The human Burkitt's lymphoma B cell line Ramos (RA1; ATCC, Manassas, Virginia, USA) was used as positive control for AID and for
EGLT expression, the later after stimulation with IL4 $(10 \mathrm{ng} / \mathrm{ml})$ and soluble CD40 ligand ( $5 \mathrm{mg} / \mathrm{ml})$ for $48 \mathrm{~h}$. The human IgEbearing cell line U266B1 (ATCC) was used as positive control for IgE mRNA. Nuclease-free water was used as negative control.

\section{Real-time PCR analysis}

IL4, IL13 and the heavy chain of the IgE gene (CE) were first amplified by PCR and sequenced to confirm their identity. PCR products were used to build a standard curve for the real-time PCR reaction by means of the LightCycler instrument and LightCycler FastStart DNA Master SYBR Green I as a ready-touse reaction mix (Roche Diagnostics, Indianapolis, Indiana, USA). Primers used were: IL4F (5'-ACATCTTTGCTGCCT CCAA), IL4R (5'-AGGCAGCGAGTGTCCTTCT); IL13F (5'ACAGCCCTCAGGGAGCTCAT), IL13R (5'-TCAGGTTGATG CTCCATACCAT); CEF (5'-CACGCTCTCTGGTCACTATG) and $\mathrm{C} \varepsilon \mathrm{R}$ (see above). Amplification conditions were denaturation at $96^{\circ} \mathrm{C}$ for $10 \mathrm{~min}$, followed by 40 cycles of denaturation at $96^{\circ} \mathrm{C}$ for $5 \mathrm{~s}$, annealing at $60^{\circ} \mathrm{C}$ (IL4 and IL13), or $65^{\circ} \mathrm{C}(\mathrm{C} \varepsilon)$ for $15 \mathrm{~s}$ and elongation at $72^{\circ} \mathrm{C}$ for $15 \mathrm{~s}$. The expression of the different transcripts was normalised to GAPDH, and results are expressed as fold induction with respect to the CTL group.

\section{Statistical analysis}

All histological samples were randomly coded, and sections were counted blinded, independent of the clinical protocol. The $\chi^{2}$ test was used for comparison of frequencies of GLTs and IgE transcripts. Numeric variables were analysed with the nonparametric Mann-Whitney U test. Correlation between CD20 ${ }^{+}$ cells and tryptase ${ }^{+}$counts was analysed using the Spearman rank correlation test. A value of $p<0.05$ was considered statistically significant.

\section{RESULTS}

\section{B lymphocytes and mast cells in the oesophageal mucosa}

The presence of $B$ cells was rarely detected in the epithelium of CTL patients. However, the oesophageal epithelium of EO patients showed significantly higher density of scattered B lymphocytes, mainly in the peripapillary area, compared to CTL patients. The vascular papillae of EO samples also showed more $\mathrm{CD} 20^{+}$cells than the CTL samples, and no difference was observed in the lamina propria (fig 1A,B). Interestingly, atopic and non-atopic patients followed similar distribution within the EO and CTL groups. Furthermore, microarray analysis revealed that EO patients have higher expression of B cell-related genes than CTL subjects (fig 1C) including immunoglobulin lambda
Figure 3 Analysis of the expression of IL4 (A) and IL13 (B) in oesophageal biopsies from EO and CTL patients. Atopic (open symbols) and non-atopic patients (dark symbols) are indicated. Each mRNA value was normalised to GAPDH mRNA expression from the same cDNA and is expressed as fold change with respect to the CTL group. The lines represent the median value in each group. EO $(n=11)$ and CTL $(n=6-8)$ groups were compared using the Mann-Whitney $U$ test. Values of $p$ are indicated. CTL, control; E0, eosinophilic oesophagitis; GAPDH, glyceraldehyde-3-phosphate dehydrogenase; IL, interleukin.
A.

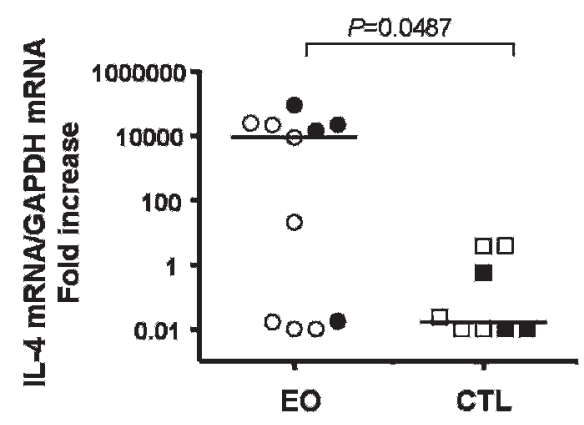

B.

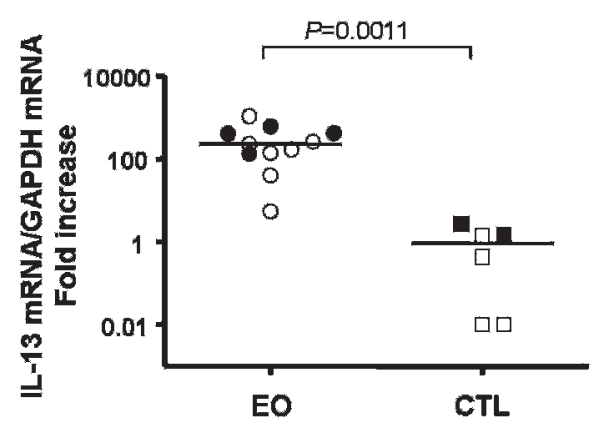


Figure 4 Analysis of the expression of GLTs in oesophageal biopsies of EO and CTL patients. Patients are divided into atopic (EO-A, $n=7$; CTL-A, $n=5$ ) and non-atopic (EO-NA, $n=4$; CTL-NA, $n=3$ ) groups. The $\varepsilon \mathrm{GLT}, 379$ bp; $\mu \mathrm{GLT}, 529$ bp; and $\gamma 4 \mathrm{GLT}, 505$ bp bands were PCR amplified from oesophageal biopsies of EO and CTL patients. GAPDH was amplified to control cDNA loading. Lanes + and - correspond to PCR positive and negative controls, respectively. A $1 \mathrm{~kb}$ plus DNA ladder was loaded in all cases. Gels are representative of one of three independent PCR amplifications yielding similar results. CTL, control; EO, eosinophilic oesophagitis; GAPDH, glyceraldehyde-3-phosphate dehydrogenase; GLTs, germ-line transcripts; PCR, polymerase chain reaction.
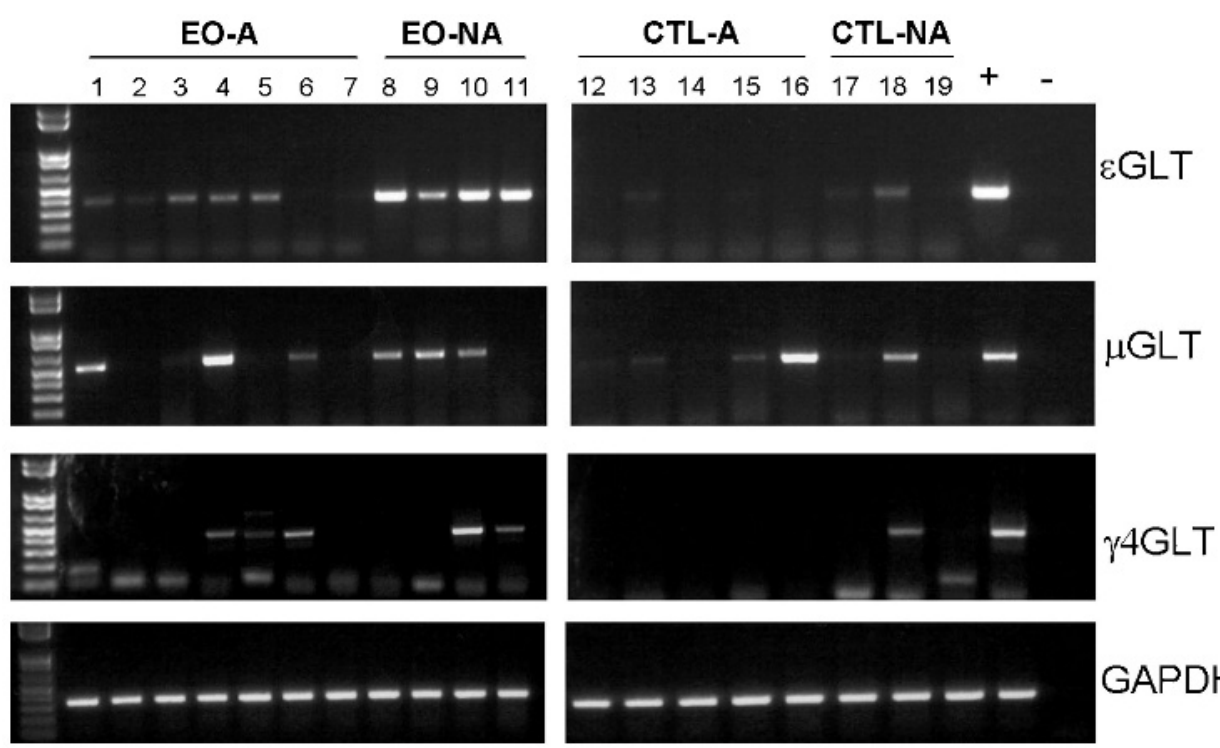

GAPDH joining 3 , immunoglobulin heavy constant delta, immunoglobulin J polypeptide and B cell RAG-associated protein (with a 12.3-, 12.1-, 8.8- and 1.9-fold increase, respectively $(p<0.001)$ ). Mast cell infiltration was also increased in EO compared to CTL samples (fig 2), as previously shown ${ }^{10} 18{ }^{19}$ with similar distribution of atopic and non-atopic subjects within each group. Notably, the density of $\mathrm{CD} 20^{+}$cells positively correlated with mast cells ( $p=0.0015 ; r^{2}=0.554$; fig $2 B$ ), but not with eosinophils in the epithelium (data not shown). Positive control staining procedure for human tonsils or nasal polyp revealed the presence of $B$ cells and mast cells, respectively, and negative control procedure did not detect any positive cells (data not shown).

\section{Expression of IL4 and IL13}

Real-time PCR demonstrated that IL4 mRNA expression was increased in EO compared with CTL, particularly in a subset of EO patients (fig $3 \mathrm{~A}$ ), with no difference related to atopy, and that IL13 mRNA was over-produced in EO, as previously shown. ${ }^{22}$ Interestingly, atopic and non-atopic EO patients had comparable levels of IL13 mRNA (fig 3B).

\section{Expression of GLT in the oesophageal mucosa}

The transcription of GLTs is essential for CSR and is the first step in the commitment of B cells to the synthesis of IgG, IgA and IgE. We detected $\varepsilon$ GLT, $\mu$ GLT and $\gamma 4$ GLT (fig 4) but not aGLT, $\gamma 1$ GLt or $\gamma 3$ GLT (data not shown) in oesophageal biopsies. The frequency of expression of total GLTs was higher in EO patients $(p=0.012)$, being individually nine of $11 \mathrm{EO}$, and three of eight CTL for $\operatorname{EGLT}(p=0.024)$; six of 11 $\mathrm{EO}$, and four of eight CTL for $\mu \mathrm{GLT}(\mathrm{p}=0.456)$; and five of 11 $\mathrm{EO}$, and one of eight CTL for $\gamma 4 \mathrm{GLT}(p=0.064)$. Interestingly, GLTs were similarly detected in both atopic and non-atopic EO patients. All PCR products were gelextracted and sequenced to confirm their identity with the corresponding IgH chain sequences present in GeneBank (data not shown).
Figure 5 Analysis of the expression of AID in oesophageal biopsies of EO and CTL patients. Patients are divided into atopic (EO-A, $n=7$; CTL-A, $n=5$ ) and non-atopic (EO-NA, $n=4$; CTL-NA, $n=3$ ) groups. The $335 \mathrm{bp}$ AID mRNA band was amplified in a semi-nested PCR. GAPDH was amplified to control cDNA loading. Lanes + and - correspond to PCR positive and negative controls, respectively. The two negative - lanes indicate first-round and second-round PCR-negative controls. A $1 \mathrm{~kb}$ plus DNA ladder was loaded. Gels are representative of one of three independent PCR amplifications yielding similar results. AID, activation-induced cytidine deaminase; CTL, control; EO, eosinophilic oesophagitis; GAPDH, glyceraldehyde-3-phosphate dehydrogenase; PCR, polymerase chain reaction.
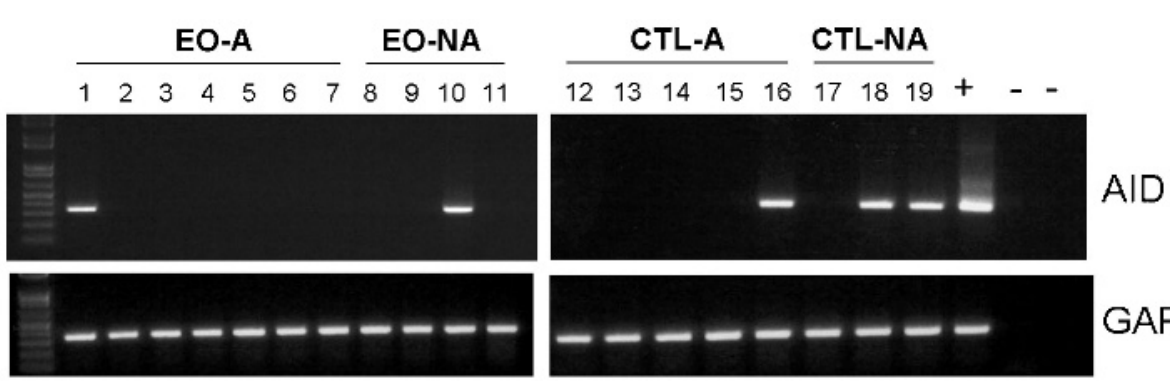

GAPDH 


\section{Expression of AID in the oesophageal mucosa}

The enzyme AID catalyses the initial step of CSR in germinalcentre B cells, and has recently been detected outside lymphoid structures. ${ }^{32}{ }^{33}$ Here, we detected AID expression in biopsies from both groups, indicating the potential of the oesophageal mucosa to undergo CSR (fig 5). PCR products from all samples were sequenced and identified as human AID mRNA (data not shown).

Expression of IgE heavy chain mRNA in the oesophageal mucosa All EO subjects showed higher expression of C $\varepsilon$ than CTL patients, as determined by quantitative PCR (fig 6). The amplified PCR product is representative of either the sterile transcripts or the mature IgE mRNA, and is increased in biopsies from both atopic and non-atopic EO patients. These data confirm, at least at the mRNA level, that local IgE expression is a feature of the oesophageal mucosa of $\mathrm{EO}$, regardless of the atopic status.

\section{Expression of mature $\lg E$ mRNA in the oesophageal mucosa}

The final step of CSR is antibody production. Mature IgE mRNA was detected in five of $11 \mathrm{EO}$, regardless of atopy, and in one of eight CTL subjects (fig 7). Differences in the frequency of expression did not reach statistical significance between $\mathrm{EO}$ and CTL $(p=0.0635)$. Importantly, and consistent with the data presented herein, detection of mature IgE mRNA suggests in situ production of $\operatorname{IgE}$ in the oesophageal mucosa, independent of the atopic status of the patient.

\section{Detection of IgE-bearing cells in the oesophageal epithelium}

We detected three different cell populations in the oesophageal epithelium based on IgE and CD117 positivity (fig 8). $\operatorname{IgE}^{+}$cells were detected only in EO and mast cells were present in both groups; however, only the EO group showed IgE-bearing mast cells. Of the total intraepithelial mast cells, the percentage of $\mathrm{IgE}^{+}$cells was increased in atopic compared to non-atopic EO patients ( $85.6 \%$; $95 \%$ CI, 70 to 100 ; and $43.8 \%, 95 \%$ CI 5.2 to 82 , respectively, $\mathrm{p}<0.05)$. Notably, the epithelium contained a

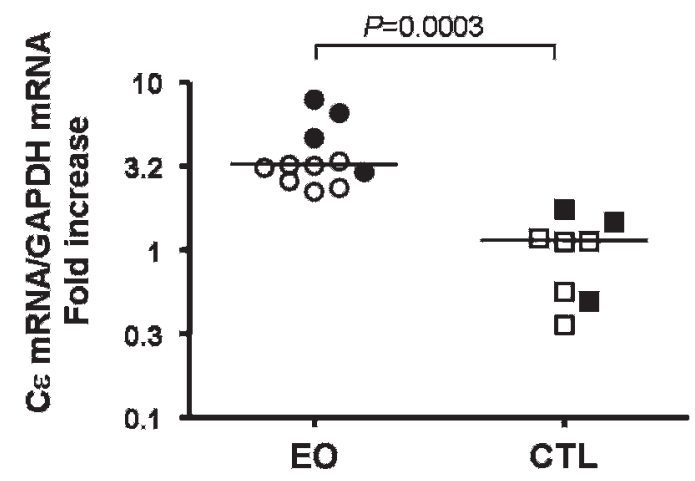

Figure 6 Analysis of the expression of $C \varepsilon$ by real-time PCR in the oesophageal biopsies of EO and CTL patients. Atopic (open symbols) and non-atopic patients (dark symbols) are indicated. Each mRNA value is normalised to GAPDH mRNA expression from the same sample and is expressed as fold increase compared to the CTL group. The lines represent the median value in each group. EO $(n=11)$ and CTL $(n=8)$ groups were compared using the Mann-Whitney $U$ test. The $p$ value is indicated. CTL, control; EO, eosinophilic oesophagitis; GAPDH, glyceraldehyde-3-phosphate dehydrogenase; PCR, polymerase chain reaction. population of $\mathrm{IgE}^{+} \mathrm{CD}^{-117^{-}}$cells which was absent in $\mathrm{CTL}$ subjects.

\section{DISCUSSION}

Eosinophilic oesophagitis is a chronic inflammatory disease in which the presence of mediators such as IL5, IL13 and eotaxin, the cellular infiltrate (eosinophils, mast cells and lymphocytes), and the association with allergic disorders, all point to a Th2associated disease. A prominent feature of the Th2 immune response is antibody production; however, the participation of $B$ cells in the pathogenesis of $\mathrm{EO}$ has not been extensively studied, probably because of the low amount of infiltrating B cells as compared with other immunocytes in the oesophageal epithelium. Our study also shows that B lymphocytes are moderately increased, consistent with studies in adult EO patients, ${ }^{18}{ }^{19}$ suggesting a similar pathogenic process in both adults and children. Notably, since B cell infiltration may mainly occur through the vascular supply of the epithelium, the increase in B lymphocytes in the vascular papillae, consistent with that of the epithelium, suggests that $B$ cell recruitment is an active process in the oesophageal mucosa in EO disease. Furthermore, differential expression of immunoglobulin genes and other $\mathrm{B}$ cell genes in EO compared to CTL subjects, together with IgE production in the oesophageal mucosa, highlight B cells as important contributors to EO pathogenesis.

CSR has been restricted to lymphoid tissues; however, recent studies have proved this phenomenon at certain mucosal sites. ${ }^{32}{ }^{33}$ The present study has discovered the expression of GLT, AID, $\mathrm{C} \varepsilon$ and IgE mRNA in the human oesophagus, providing the first evidence for local class switching to IgE and IgE production, and actually indicating that the oesophageal mucosa is primed for switching to IgE in EO. GLT expression demonstrates the potential of $\mathrm{B}$ cells to undergo CSR, but it does not provide definitive evidence that switching has actually occurred. ${ }^{38}$ In order to confirm the ongoing process, the presence of either switch circles or circular transcripts needs to be demonstrated. ${ }^{27}{ }^{39}$ However, since none of those molecular markers were detected in EO biopsies (data not shown), we cannot exclude the possibility that B cells switched elsewhere and migrated to the oesophagus. Nevertheless, the expression of switch circles and circular transcripts is transient, and they are not detected unless switching has taken place recently. ${ }^{38}$ In order to detect ongoing switching, it may be necessary to collect biopsies precisely at the time of exposure to the allergen, as has been done in rhinitis patients during the allergy season. ${ }^{32}$ In our study, specimen collection was performed during the course of the disease, and did not take into account whether patients were avoiding exposure to specific foods prior to the endoscopy; indeed, as part of the preparation, patients are fasted overnight. This may explain why switch circles or circular transcripts were undetectable in our samples. According to the hypothesis that switching already occurred when biopsies were collected, CD40L was not upregulated in EO (data not shown), as it is rapidly and transiently expressed on recently stimulated $T$ helper cells and antigen-presenting cells upon activation..$^{40}{ }^{41}$

Atopy is more prevalent in subjects who have EO than in the general population. ${ }^{6}{ }^{12}$ Clinical studies have shown a high prevalence of atopic diseases in EO patients. ${ }^{6}{ }^{13}$ In our study, rhinitis had the highest prevalence among atopic manifestations $(55 \%)$, highlighting a possible link between the immune response in the respiratory tract and the oesophageal mucosa. Notably, intranasal, but not oral or intragastric allergen challenge induces experimental $\mathrm{EO}^{42}$ suggesting a role for inhaled allergens. Nonetheless, not all EO patients have clinical 
Figure 7 Analysis of the expression of mature IgE mRNA in oesophageal biopsies of EO and CTL patients. Patients are divided into atopic (EO-A, $n=7$; CTL$A, n=5$ ) and non-atopic (EO-NA, $n=4$; CTL-NA, $n=3$ ) groups. The 412 bp $\lg E$ band was PCR amplified from oesophageal biopsies of EO and CTL patients, and GAPDH was amplified to control cDNA loading. Lanes - and + correspond to PCR negative and positive controls, respectively. A 1 kb plus DNA ladder was loaded. Gels are representative of one of three independent PCR amplifications yielding similar results. CTL, control; EO, eosinophilic oesophagitis; GAPDH, glyceraldehyde-3-phosphate dehydrogenase; PCR, polymerase chain reaction.

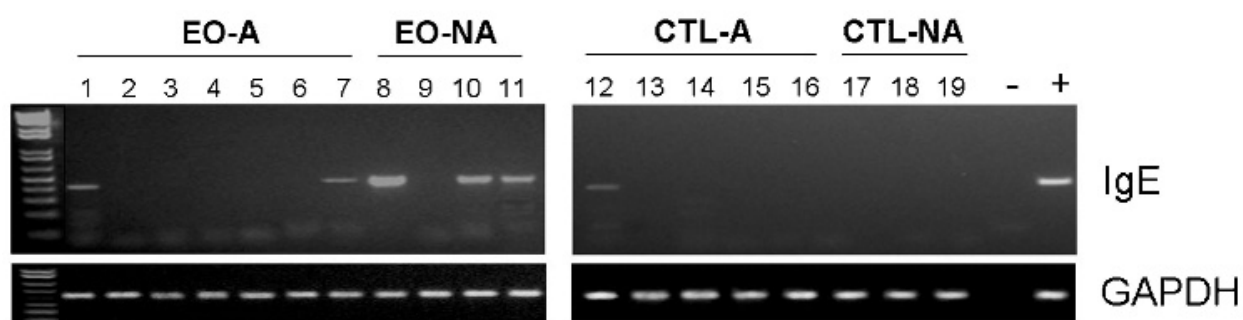

manifestations of atopy or show positivity to SPT and this fact led us to analyse the Th2 response in atopic and non-atopic EO patients and to compare it with the same two groups in CTL patients. Interestingly, the recently identified EO transcript signature has been proven to be remarkably conserved between patients despite their age, sex, familial inheritance pattern and
Figure 8 Detection of $\lg \mathrm{E}^{+}$and $\mathrm{CD} 117^{+}$ cells in the oesophageal epithelium by double immunofluorescence. (A)

Representative micrographs of the oesophageal epithelium where lgEbearing cells (red) and mast cells (green) are identified (arrow head). An example of CTL and EO biopsies ( $a$ and $b$ micrographs, respectively) is shown, where epithelial hyperplasia, elongation of the vascular papillae (P) and eosinophils (asterisk) are detected (low-power field, $\times 200$ ). The three identified populations are shown in groups of three micrographs each, at high-power field $(\times 600)$ : $\lg \mathrm{E}^{+} \mathrm{CD} 117^{+}(\mathrm{c}, \mathrm{d}, \mathrm{e}) ; \lg \mathrm{E}^{+} \mathrm{CD} 117^{-}(\mathrm{f}, \mathrm{g}, \mathrm{h})$; $\lg \mathrm{E}^{-} \mathrm{CD} 117^{+}(\mathrm{i}, \mathrm{j}, \mathrm{k})$. (B) Quantification of the cell populations based on $\lg E$ and CD117 positivity in the oesophageal epithelium of EO $(n=16)$ and CTL $(n=7)$ patients. The maximum number of positive cells per reticle is represented in each group. Atopic (open symbols) and non-atopic patients (dark symbols) are indicated. CTL, control; EO, eosinophilic oesophagitis.
A.

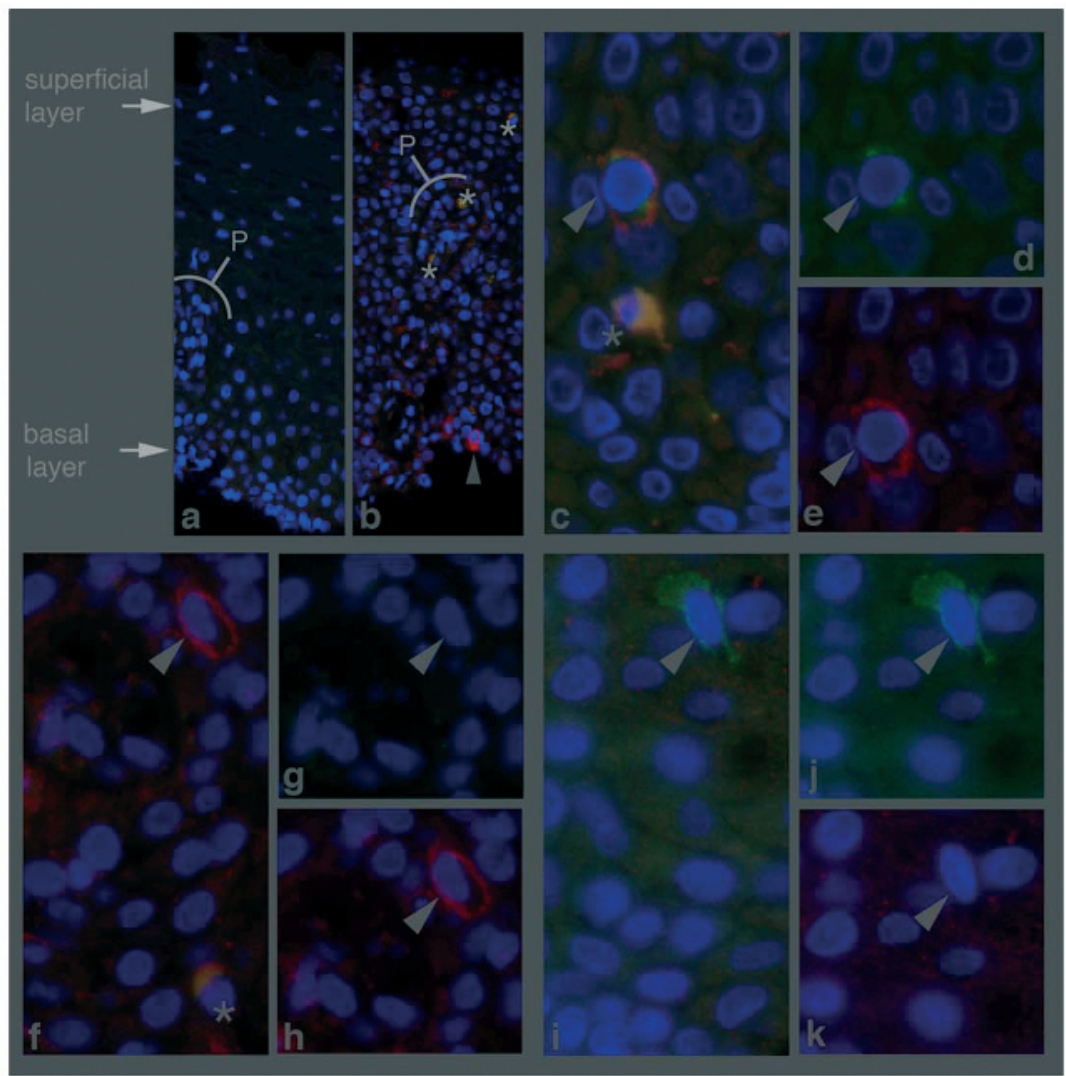

B.
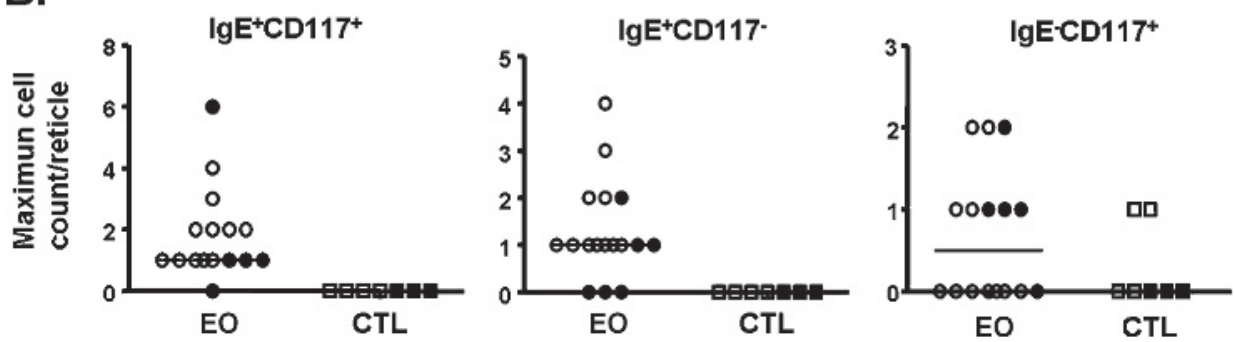
allergic status, suggesting that allergic and non-allergic variants of EO have a common underlying pathogenesis. ${ }^{6}{ }^{10}$ Those results imply that the present study's findings of accumulation of $B$ cells expressing molecular markers of CSR and detection of IgE production would be comparable across both clinically defined atopic and non-atopic EO patients. Indeed, and importantly, perhaps "non-atopic" EO patients are actually atopic, but to a lesser extent.

IL4 and IL13 have a key role in the induction of IgE switching by stimulating transcription from the germline promoter site of IgE, via STAT6 sites, ${ }^{23}$ and are also B cell proliferating factors. ${ }^{43}$ Here we confirmed over-expression of IL13 mRNA in EO $\mathrm{E}^{22}$ and demonstrated that transcription of IL13 is not influenced by the atopic status of the patient. We have previously shown that the expression of IL4 in EO patients is similar to control patients although there was great heterogeneity in levels, ${ }^{22}$ perhaps because, in that previous study, patients with EO were selected regardless of therapy. However, when selecting non-corticosteroid and non-dietary treated EO patients, IL4 mRNA proved higher in EO than in CTL patients. Importantly, the participation of IL4 in promoting Th2 responses and stimulating class switching to IgG4 and $\operatorname{IgE} \mathrm{E}^{23} 44$ is suggested here, as demonstrated by the expression of $\varepsilon$ GLT and $\gamma 4$ GLT in EO subjects.

The presence of $\mathrm{IgE}^{+}$cells in the oesophageal epithelium has been shown previously in EO, and it has been assumed that those IgE-bearing cells were all mast cells. ${ }^{17-19}$ Herein, we demonstrate that IgE-sensitised mast cells are a feature of the EO epithelium, and also that the percentage of mast cells linked to $\operatorname{IgE}$ is increased in atopic compared to non-atopic EO patients. Mechanisms other than antigen cross-linking of IgE on the surface also activate mast cells to release mediators. Of importance to EO, eosinophils and mast cells both secrete mediators relevant for mutual activation and survival. ${ }^{45}$ In our study, two populations of intraepithelial mast cells were detected based on IgE surface positivity, suggesting different coexisting mechanisms of activation of mast cells in $\mathrm{EO}$. Notably, the correlation between $\mathrm{CD} 20^{+}$cells and tryptase ${ }^{+}$ cells, the expression of IgE mRNA and the density of $\operatorname{IgE} \mathrm{E}^{+} \mathrm{CD} 117^{+}$in $\mathrm{EO}$, suggest that IgE-mediated mast cell activation importantly contributes to disease pathogenesis.

Of interest, we report a population of IgE-bearing cells lacking CD117 expression. Eosinophils could account for this population, since they express FceRI and FceRII. ${ }^{46}$ However, they are highly autofluorescent, and observation under a fluorescence microscope confirmed that none of them were bound to $\operatorname{IgE}$. Memory B cells and plasmablasts can express IgE and are likely to represent that $\mathrm{IgE}^{+} \mathrm{CD} 117^{-}$population. In patients with allergic rhinitis, approximately $4 \%$ of the B cells and $15 \%$ of plasma cells express IgE in the nasal mucosa and, in that situation, it has been suggested that the maturation of IgEexpressing B cells (activated or memory) to IgE-producing plasma cells takes place locally. ${ }^{47}$ The presence of $B$ cells and of $\mathrm{IgE}^{+}$cells in the oesophageal epithelium has been proven previously. ${ }^{17-19}$ In our study, the appearance of $\mathrm{B}$ cells primed to isotype switch and the detection of $\operatorname{IgE} \mathrm{mRNA}$, led us to hypothesise that mature $B$ cells are locally challenged by allergen, followed by the formation of IgE-memory B cells and IgE plasmablasts. In keeping with this, we also showed increased expression of immunoglobulin and stimulating B cell genes in EO. However, we do not exclude the possibility that already stimulated B lymphocytes at other mucosal sites infiltrate the epithelium where, upon allergen stimulation, they locally mature to IgE plasmablasts. Notably, the high rate of transcription of the IGJ gene in EO biopsies, points at plasmablasts as candidates for those $\operatorname{IgE}^{+} \mathrm{CD} 117^{-}$cells, since the Ig $J$ chain gene is expressed only after the terminal differentiation of $\mathrm{B}$ cells towards plasma cells. ${ }^{48}$

In summary, we have demonstrated increased B cells and expression of molecular Ig machinery (eg, Ig genes and recombination enzymes) in the oesophageal mucosa of paediatric patients with EO regardless of the atopic status. Furthermore, we have determined that $\operatorname{IgE}^{+}$cells (especially mast cells) are a specific feature of EO compared with control individuals. As such, we propose that the oesophageal mucosa is a site for initiation and development of humoral responses. These results offer an explanation for the dissociation between skin-prick test results and food elimination diets in EO.

Acknowledgements: The authors thank Dr P Takhar for advice in performing IgE mRNA PCR, Dr CA Chougnet for kindly providing the sCD40L, and B Dipasquale and M Rolfes for performing immunohistochemical and immunofluorescence procedures.

Funding: This work was funded, in part, by the Spanish Ministry of Sanidad y Consumo, Subdirección General de Investigación Sanitaria, Instituto Carlos III, Fondo de Investigación Sanitaria (CD05/00060, to MV; PI05/1423 \& EC07/90148, to JS); the International Foundation for Functional Gastrointestinal Disorders (IFFGD 01/2008, to JS); the Thrasher Research Fund (NR-0014, to CB); the PHS Grant P30 DK0789392, the NIH (Al070235, Al45898 and DK076893, to MER; Al079874, to CB); the Food Allergy and Anaphylaxis Network (FAAN, to MER); Campaign Urging Research for Eosinophil Disorders (CURED, to MER); the Buckeye Foundation (to MER); the Food Allergy Project (to MER); and the DDRDC (NIDDK 064403, to MER). The study sponsors had no involvement in study design; in the collection, analysis, and interpretation of data; in the writing of the report; or in the decision to submit the paper for publication.

Competing interests: MER receives financial and/or stock compensation as a consultant and/or speaker for Merck, Ception Therapeutics, Novartis, Nycomed, and Centocor. The other authors have no competing interests.

Ethics approval: The study and the collection of specimens were approved by the Cincinnati Children's Hospital Medical Center Institutional Review Board.

Provenance and peer review: Not commissioned; externally peer reviewed.

\section{REFERENCES}

1. Fox VL, Nurko S, Furuta GT. Eosinophilic esophagitis: it's not just kid's stuff. Gastrointestinal Endosc 2002;56:260-70.

2. Orenstein SR, Shalaby TM, Di Lorenzo C, et al. The spectrum of pediatric eosinophilic esophagitis beyond infancy: a clinical series of 30 children. Am J Gastroenterol 2000;95:1422-30.

3. Straumann A, Spichtin HP, Grize L, et al. Natural history of primary eosinophilic esophagitis: a follow-up of 30 adult patients for up to 11.5 years. Gastroenterology 2003:125:1660-9.

4. Kerlin P, Jones D, Remedios M, et al. Prevalence of eosinophilic esophagitis in adults with food bolus obstruction of the esophagus. J Clin Gastroenterol 2007;41:356-61.

5. Noel RJ, Putnam PE, Rothenberg ME. Eosinophilic esophagitis. N Engl J Med 2004;351:940-1.

6. Collins $\mathbf{M H}$, Blanchard C, Abonia JP, et al. Clinical, pathologic, and molecular characterization of familial eosinophilic esophagitis compared with sporadic cases. Clin Gastroenterol Hepathol 2008;6:621-9.

7. Stainer SJ, Gupta SK, Croffie JM, et al. Correlation between number of eosinophils and reflux index on same day esophageal biopsy and 24 hour esophageal $\mathrm{pH}$ monitoring. Am J Gastroenterol 2004;99:801-5.

8. Walsh SV, Antonioli DA, Goldman H, et al. Allergic esophagitis in children: a clinicopathological entity. Am J Surg Pathol 1999;23:390-6.

9. Rothenberg ME, Mishra A, Collins MH, et al. Pathogenesis and clinical features of eosinophilic esophagitis. J Allergy Clin Immunol 2001;108:891-4.

10. Blanchard C, Wang N, Stringer KF, et al. Eotaxin-3 and a uniquely conserved geneexpression profile in eosinophilic esophagitis. J Clin Invest 2006;116:536-47.

11. Rothenberg ME. Eosinophilic gastrointestinal disorders (EGID). J Allergy Clin Immunol 2004:113:11-28.

12. Assa'ad A. Eosinophilic esophagitis: association with allergic disorders. Gastrointest Endoscopy Clin N Am 2008;18:119-32.

13. Roy-Ghanta S, Larosa DF, Katzka DA. Atopic characteristics of adult patients with eosinophilic esophagitis. Clin Gastroenterol Hepatol 2008:6:531-5.

14. Markowitz JE, Spergel JM, Ruchelli E, et al. Elemental diet is an effective treatment for eosinophilic esophagitis in children and adolescents. Am J Gastroenterol 2003:98:777-82.

15. Kagalwalla AF, Sentongo TA, Ritz $\mathbf{S}$, et al. Effect of six-food elimination diet on clinical and histologic outcomes in eosinophilic esophagitis. Clin Gastroenterol Hepatol 2006:4:1097-102. 
16. Spergel JM, Andrews T, Brown-Whitehorn TF, et al. Treatment of eosinophilic esophagitis with specific food elimination diet directed by a combination of skin prick and patch tests. Ann Allergy Asthma Immunol 2005;95:336-43.

17. Kirsch R, Bokhary R, Marcon MA, et al. Activated mucosal mast cells differentiate eosinophilic (allergic) esophagitis from gastroesophageal reflux disease. J Pediatr Gastroenterol Nutr 2007:44:20-6.

18. Lucendo AJ, Navarro M, Comas C, et al. Immunophenotypic characterization and quantification of the epithelial inflammatory infiltrate in eosinophilic esophagitis through steorology. Am J Surg Pathol 2007:31:598-606.

19. Straumann A, Bauer M, Fischer B, et al. Idiopathic eosinophilic esophagitis is associated with a Th2-type allergic inflammatory response. J Allergy Clin Immunol 2001:108:954-61.

20. Collins MH. Histopathologic features of eosinophilic esophagitis. Gastrointest Endosc Clin N Am 2008:18:59-71.

21. Blanchard C, Rothenberg ME. Basic pathogenesis of eosinophilic esophagitis. Gastrointest Endosc Clin N Am 2008;18:133-43.

22. Blanchard C, Mingler MK, Vicario M, et al. IL-13 involvement in eosinophilic esophagitis: Transcriptome analysis and reversivility with glucocorticoids. J Allergy Clin Immunol 2007:120:1292-300.

23. Gould HJ, Sutton BJ, Beavil AJ, et al. The biology of IgE and the basis of allergic disease. Annu Rev Immunol 2003:21:579-628.

24. Stavnezer J. Antibody class switching. Adv Immunol 1996;61:79-146.

25. Cerutti A, Zan H, Schaffer A, et al. CD40 ligand and appropriate cytokines induce switching to lgG, IgA, and lgE and coordinated germinal center and plasmacytoid phenotypic differentiation in a human monoclonal $\lg \mathrm{M}+\lg \mathrm{D}+\mathrm{B}$ cell line. J Immunol 1998:160:2145-57.

26. Muramatsu M, Kinoshita K, Fagarasan S, et al. Class switch recombination and hypermutation require activation-induced cytidine deaminase (AID), a potential RNA editing enzyme. Cell 2000;102:553-63.

27. Stavnezer J, Guikema EJ, Schrader C. Mechanism and regulation of class switch recombination. Annu Rev Immunol 2008;26:261-92.

28. Liu YJ, Malisan F, de Bouteiller O, et al. Within germinal centers, isotype switching of immunoglobulin genes occurs after the onset of somatic mutation. Immunity 1996:4:241-50.

29. Toellner KM, Gulbranson JA, Taylor DR, et al. Immunoglobulin switch transcript production in vivo related to the site and time of antigen-specific B cell activation J Exp Med 1996;183:2303-12.

30. Fagarasan S, Kinosita K, Muramatsu M, et al. In situ class switching and differentiation to IgA-producing cells in the gut lamina propria. Nature 2001;413:639-43.

31. Fagarasan S, Muramatsu M, Suzuki K, et al. Critical roles of activation-induced cytidine deaminase in the homeostasis of gut flora. Science 2002:298:1424-7.
32. Takhar $\mathbf{P}$, Smurthwaite $\mathrm{L}$, Coker HA, et al. Allergen drives class switch to lgE in the nasal mucosa in allergic rhinitis. J Immunol 2005;174:5024-32.

33. Takhar $\mathbf{P}$, Corrigan CJ, Smurthwaite L, et al. Class switch recombination to $\lg E$ in the bronchial mucosa of atopic and nonatopic patients with asthma. J Allergy Clin Immunol 2007;119:213-8.

34. Waldmann T, lio A, Ogawa M, et al. The metabolism of IgE. Studies in normal individuals and in a patient with lgE myeloma. J Immunol 1976;117:1139-44.

35. Matsumoto K, Shimada T, Uchida Y. Morphology of the lamina propria in the esophagus with special reference to he proprial papillae. Med Electron Microsc 1997; 30:15-24.

36. Zimmermann N, King NE, Laporte J, et al. Dissection of experimental asthma with DNA microarray analysis identifies arginase in asthma pathogenesis. J Clin Invest 2003:111:1863-74.

37. Ravetch JV, Siebenlist U, Korsmeyer S, et al. Structure of the human immunoglobulin mu locus: characterization of embryonic and rearranged $\mathrm{J}$ and $\mathrm{D}$ genes. Cell 1981;27:583-91.

38. Gould HJ, Takhar P, Harries HE, et al. Germinal-centre reactions in allergic inflammation. Trends Immunol 2006:27:446-52.

39. Kinoshita K, Harigai M, Fagarasan $\mathrm{S}$, et al. A hallmark of active class switch recombination: transcripts directed by I promoters on looped out circular DNAs. Proc Natl Acad Sci USA 2001;98:12620-3.

40. MacDonanld KPA, Nishioka Y, Lipsky PE, et al. Functional CD40 ligand is expressed by T cells in rheumatoid arthritis. J Clin Invest 1997:100:2404-14.

41. McHeyzer-Williams JL, McHeyzer-Williams MG. Antigen-specific memory B cell development. Annu Rev Immunol 2005;23:487-513

42. Misha A, Hogan SP, Brandt EB, et al. An etiological role for aeroallergens and eosinophils in experimental esophagitis. J Clin Invest 2001;107:83-90.

43. Cocks BG, de Waal Malefiyt R, Galizzi JP, et al. IL-13 induces proliferation and differentiation of human B cells activated by the CD40 ligand. Int Immunol 1993:5:657-63

44. Sehra S, Bruns HA, Ahyi AN, et al. IL-4 is a critical determinant in the generation of allergic inflammation initiated by a constitutively active STAT6. J Immunol 2008; 180:3551-9.

45. Piliponsky AM, Gleich GJ, Bar I, et al. Effects of eosinophils on mast cells: a new pathway for the perpetuation of allergic inflammation. Mol Immunol 2002;38:1369-72.

46. Kita H, Kaneko M, Bartemes KR, et al. Does IgE bind to and activate eosinophils from patients with allergy? J Immunol 1999:162:6901-11.

47. KleiJan A, Vinke JG, Severijnen LW, et al. Local production and detection of (specific) IgE in nasal B-cells and plasma cells of allergic rhinitis patients. Eur Respir J 2000;15:491-7.

48. Koshland ME. The coming of age of the immunoglobulin J chain. Annu Rev Immunol 1985; 3:425-53. 